\title{
Inhalation Induction in Tracheostomized Patients: Comparison of Desflurane and Sevoflurane
}

\section{Kerem Erkalp, $M D^{1}$, Nuran Kalekoglu Erkalp, $M D^{2}$, Veysel Erden, $M D^{3}$, Arzu Yasemin Korkut, $M D^{2}$, and Yesim Cokay Abut, $M D^{3}$}

\author{
${ }^{1}$ Anesthesiology and Reanimation Specialist, Bagcilar Educational and Training Hospital, Turkey \\ ${ }^{2}$ Ear, Nose and Throat Specialist, Sisli Etfal Training Hospital, Turkey \\ ${ }^{3}$ Anesthesiology and Reanimation Specialist, Istanbul Educational and Training Hospital, Turkey
}

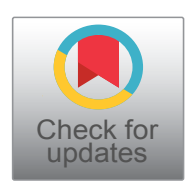

*Corresponding author: Kerem Erkalp, MD, Assc. Prof, Anesthesiology and Reanimation Specialist, Bagcilar Educational and Training Hospital, Senlikkoy Mah. Eksinar Sok. No: 44, Eksinar Konakları, A2-1 Blok, Daire:5, Florya/Bakırköy, Turkey

\section{Abstract}

Background: Inhalation induction (II) of anesthesia is a commonly used method in difficult airway management, pediatric anesthesia and also tracheostomized patients' surgical practices. Sevoflurane and desflurane are the most common inhalation agents for II in these procedures of patients. We demonstrated that II with sevoflurane or desflurane in tracheostomized patients who are not studied up until now and their outcomes. Cardiorespiratory changes in II should be the same in tracheostomized patients with desflurane compared to sevoflurane.

Methods: We studied 60 adult tracheostomized patients (ASA physical status 2 or 3 ), scheduled for elective surgery under general anesthesia. Patients were allocated randomly to receive either desflurane (Group D) or sevoflurane (Group S) for II. Following $1 \mathrm{mg}$ midazolam and $1 \mu \mathrm{g} / \mathrm{kg}$ fentanyl, all patients were intubated via tracheostomy with a montandon tracheostomy tube. In the Group D, patients were firstly instructed to breath and then they immediately started using desflurane and $50 \%$ nitrous oxide in oxygen $(3 / 3 \mathrm{~L})$. Desflurane was introduced at an inspired concentration of $3 \%$ and increased by $1 \%$ every $4-6$ breaths as tolerated, up to a maximum of $12 \%$. In the Group S, patients were also instructed to breathe firstly and then they immediately started using sevoflurane and $50 \%$ nitrous oxide in oxygen $(3 / 3 \mathrm{~L})$. Sevoflurane was introduced at an inspired concentration of $1 \%$ and increased by $0.3 \%$ every $4-6$ breaths as tolerated, up to a maximum of $6 \%$. Hemodynamic values $\left[\left(\mathrm{SpO}_{2}\right.\right.$, heart rate $(\mathrm{HR})$ and arterial pressure (MAP)], respiratory complications (coughing, bronchospasm, desaturation, breath-holding), purposeful movement of limbs, secretions requiring removal by suction, time to loss of response to command and concentration of expired inhalation agent
\end{abstract}

(desflurane or sevoflurane) were recorded for 10 minutes of II. Mean, standard deviation, frequency and percentage were used for descriptive statistics with SSPS 20.0.

Results: Couching, bronchospasm, desaturation, breathholding and purposeful movements distributions did not show any differences in Group D and Group S. Requirement of secretion removal was higher in Group D. Hemodynamic values were more stable in Group S.

Conclusion: In tracheostomized patients' II; desflurane has similar airway irritation with sevoflurane but II is more stable with sevoflurane than desflurane.

\section{Keywords}

Inhalation induction, Sevoflurane, Desflurane, Tracheostomy

\section{List of Abbreviations}

II: Inhalation Induction; ENT: Ear, Nose and Throat; HR: Heart Rate; MAP: Mean Arterial Pressure; BCC: Basal Cell Carcinoma; ECG: Electrocardiography; NIBP: Noninvasive Blood Pressure; $\mathrm{SpO}_{2}$ : Oxygen Saturation by Pulse Oximetry

\section{Background}

Inhalation Induction (II) is frequently used in Ear, Nose and Throat (ENT) operations such as difficulty in airway and pediatric group [1]. Sevoflurane and desflurane are the most common inhalation agents for II in these procedures of patients [2]. They have similar low blood gas partition coefficients, therefore they provide rapid induction and early recovery [3]. II

Citation: Erkalp K, Erkalp NK, Erden V, Korkut AY, Abut YC (2019) Inhalation Induction in Tracheostomized Patients: Comparison of Desflurane and Sevoflurane. Int J Anesthetic Anesthesiol 6:089. doi. org/10.23937/2377-4630/1410089

Accepted: May 08, 2019: Published: May 10, 2019

Copyright: (C) 2019 Erkalp K, et al. This is an open-access article distributed under the terms of the Creative Commons Attribution License, which permits unrestricted use, distribution, and reproduction in any medium, provided the original author and source are credited. 
with desflurane is not popular than sevoflurane $[4,5]$. When desflurane is used II is associated with respiratory system irritation, hypertension, tachycardia [6-8].

Indications for tracheostomy are upper airway infection, trauma, tumor, obstructive sleep apnea, upper airway obstructions caused by stenosis foreign body, respiratory failure, management of secretions, promoting weaning and long term mechanical ventilation support, diaphragma weakness, aspiration, coma, and ineffective cough [9]. Tracheostomized patients may need surgery with general anesthesia in any time of their lives. In our anesthesia practice, the surgery types we commonly encounter in tracheostomized patients are a type of bladder cancer, neck dissection, Basal Cell Carcinom (BCC) Excision, mediastinoscopy, lung lobectomy, peripheral vascular and coronary bypass surgery.

We demonstrated that II with sevoflurane and/or desflurane in tracheostomized patients who are not studied up until now. We hypothesize that cardiorespiratory changes in II should be the same in tracheostomized patients with desflurane compared to sevoflurane.

\section{Methods}

After obtaining local ethics committee approval and written informed consent, we studied 60 adult tracheostomized patients (ASA physical status II or III), scheduled for elective surgery under general anesthesia at the Vakif Gureba Training Hospital, Istanbul.

Patients were unpremedicated. In the operating room, after cannulating a suitable vein, standard monitors [Heart Rate (HR) and rhythm by 5-lead Electrocardiography (ECG), Noninvasive Blood Pressure (NIBP), oxygen saturation by pulse oximetry $\left.\left(\mathrm{SpO}_{2}\right)\right]$ were applied and the patients were allocated randomly to receive either desflurane (Group D) or sevoflurane (Group S) for inhalation induction. Following the intravenous administrations of $1 \mathrm{mg}$ midazolam and $1 \mu \mathrm{g} / \mathrm{kg}$ fentan$\mathrm{yl}$, all patients were intubated via tracheostomy with a montandon tracheostomy tube (Portex ${ }^{\circledR}$, Smiths Medical, UK). By connecting montandon tube end to anesthesia circuit, preoxygenation with $\% 100 \mathrm{O}_{2}$ by an oxygen flow of 4 liter/min for 3 minutes under spontaneous ventilation is enabled in patients.

In the Group D, patients were firstly instructed to breath and then they immediately started using desflurane and $50 \%$ nitrous oxide in oxygen ( $3 / 3 \mathrm{~L})$. Desflurane was introduced at an inspired concentration of $3 \%$ and increased by $1 \%$ every $4-6$ breaths as tolerated, up to a maximum of $12 \%$. In the Group S, patients were also instructed to breathe firstly and then they immediately started using sevoflurane and $50 \%$ nitrous oxide in oxygen $(3 / 3 \mathrm{~L})$. Sevoflurane was introduced at an inspired concentration of $1 \%$ and increased by $0.3 \%$ every $4-6$ breaths as tolerated, up to a maximum of $6 \%$. Induction of anesthesia was considered complete when there was loss of response to command with the patient, loss of eyelash reflex, and the eyes were immobile and central.

Cardiovascular and respiratory changes were measured [10]. An observer recorded the hemodynamic values for 10 minutes, following (1) $\mathrm{SpO}_{2}$ every 30 second and the lowest $\mathrm{SpO}_{2}$ noted; (2) Heart rate (HR) and (3) Arterial pressure (MAP) every 1 minute; (4) Coughing: Each episode was recorded and graded: mild $=1-3$ coughs, moderate $=4-7$ coughs and severe $\geq 7$ coughs; (5) Bronchospasm: The observer auscultated the chest at 1-minute intervals; (6) Desaturation: $\mathrm{SpO}_{2}<90 \%$; (7) Breath-holding: Each episode was recorded and graded: mild $\leq 10$ second, moderate $=10-20$ second and severe $\geq 20$ second; (8) Purposeful movement of limbs: Each episode was recorded and graded as mild, moderate and severe; (9) Secretions requiring removal by suction were recorded; (10) Time to loss of response to command; and (11) Concentration of expired inhalation agent (desflurane or sevoflurane) when anesthesia was induced.

All surgical operations were started after 10-minute-measures in order to avoid sympathetic response. Statistical methods: Mean, standard deviation, frequency and percentage were used for descriptive statistics. The distribution of variables was checked with Kolmogorov-Smirnov Test. Independent samples t test and Mann-Whitney $U$ Test were used for the comparison of quantitative data. Paired samples t test and Wilcoxon Test were used for the repeated measurement analysis. Chi-Square Test was used for the comparison of the qualitative data. SSPS 20.0 was used for statistical analyses.

\section{Results}

No difference is detected in Group D and Group $S$ patients' age, gender distribution, BMI values, tracheostomized life time and ASA rates $(p>0.05)$. Time to loss of response to command was shorter in Group D than Group $S$ while concentration percentage of expired inhalation agent was higher in Group D than Group S ( $p$ $<0.05$ ) (Table 1).

Couching, bronchospasm, desaturation, breath-holding and purposeful movements distributions did not show any differences in Group D and Group S ( $p>0.05$ ). Requirement of secretion removal was higher in Group D than Group S ( $<$ 0.05) (Table 2).

Any differences were not detected in $\mathrm{SpO}_{2}$ values in seconds of pre-op- 60- 90- 120-150-180- 210- 240270- 360- 420 neither in Group D nor in Group S (p $>0.05)$. $\mathrm{SpO}_{2}$ values in seconds of 30- 300- 360 were lower in Group D than Group S ( $p<0.05)$. $\mathrm{SpO}_{2}$ values in seconds of 390-450- 480-510- 540- 570 were higher in Group D than Group S ( $<<0.05)$. $\mathrm{SpO}_{2}$ values in Group $S$ were higher till the $360^{\text {th }}$ second but after the $360^{\text {th }}$ second $\mathrm{SpO}_{2}$ values in Group D became higher (Table 3 and Figure 1). 
Table 1: No difference is detected in Group D and Group S patients 'age, gender distribution, BMI values, tracheostomized life time and ASA rates $(p>0.05)$. Time to loss of response to command was shorter in Group D than Group $S$ while concentration percentage of expired inhalation agent was higher in Group D than Group $S(p<0.05)$.

\begin{tabular}{|c|c|c|c|c|}
\hline & & \multirow{2}{*}{\begin{tabular}{|l|} 
Group D \\
Mean \pm s.d./n-\% \\
\end{tabular}} & \multirow{2}{*}{$\begin{array}{l}\text { Group S } \\
\text { Mean } \pm \text { s.d./n-\% }\end{array}$} & \multirow[t]{2}{*}{$\mathbf{p}$} \\
\hline & & & & \\
\hline \multirow[t]{2}{*}{ Gender } & Male & $27 \pm 90.0 \%$ & $28 \pm 93.3 \%$ & \multirow[b]{2}{*}{0.640} \\
\hline & Female & $3 \pm 10.0 \%$ & $2 \pm 6.7 \%$ & \\
\hline \multicolumn{2}{|l|}{ Age (year) } & $64.6 \pm 4.7$ & $65.4 \pm 6.4$ & 0.582 \\
\hline \multicolumn{2}{|l|}{ BMI $\left(\mathrm{kg} / \mathrm{m}^{2}\right)$} & $20.0 \pm 2.0$ & $19.8 \pm 1.8$ & 0.416 \\
\hline Tracheostomized life time (week) & & $106.5 \pm 77.6$ & $134.3 \pm 79.7$ & 0.177 \\
\hline \multicolumn{2}{|l|}{ Time to loss of response to command (S) } & $166.7 \pm 40.4$ & $189.3 \pm 41.0$ & 0.035 \\
\hline Expired desflurane concentration (\%) & & $6.9 \pm 0.7$ & $2.7 \pm 0.5$ & 0.000 \\
\hline \multirow[t]{2}{*}{ ASA } & II & $20 \pm 66.7 \%$ & $19 \pm 63.3 \%$ & \multirow[t]{2}{*}{0.787} \\
\hline & III & $10 \pm 33.3 \%$ & $11 \pm 36.7 \%$ & \\
\hline
\end{tabular}

Chi-square test/Independent Samples t test; BMI: Body Mass Index; ASA: American Society of Anesthesiologists.

Table 2: Coughing, bronchospasm, desaturation, breath-holding and purposeful movements distributions did not show any differences in Group D than Group S $(p<0.05)$. Requiring of secretions removal was higher in Group D than Group $S(p<0.05)$.

\begin{tabular}{|c|c|c|c|c|}
\hline & & \multirow{2}{*}{$\begin{array}{l}\text { Group D } \\
\text { Mean } \pm \text { s.d./n-\% }\end{array}$} & \multirow{2}{*}{$\begin{array}{l}\text { Group S } \\
\text { Mean } \pm \text { s.d./n-\% }\end{array}$} & \multirow[t]{2}{*}{$\mathbf{p}$} \\
\hline & & & & \\
\hline \multirow{4}{*}{ Coughing } & None & $15 \pm 50.0 \%$ & $19 \pm 63.3 \%$ & \multirow{4}{*}{0.297} \\
\hline & Mild & $6 \pm 20.0 \%$ & $4 \pm 13.3 \%$ & \\
\hline & Moderate & $4 \pm 13.3 \%$ & $5 \pm 16.7 \%$ & \\
\hline & Severe & $5 \pm 16.7 \%$ & $2 \pm 6.7 \%$ & \\
\hline \multirow[t]{2}{*}{ Bronchospasm } & No & $27 \pm 90.0 \%$ & $28 \pm 93.3 \%$ & \multirow[t]{2}{*}{0.640} \\
\hline & Yes & $3 \pm 10.0 \%$ & $2 \pm 6.7 \%$ & \\
\hline \multirow[t]{2}{*}{ Desaturation } & No & $23 \pm 76.7 \%$ & $24 \pm 80.0 \%$ & \multirow[t]{2}{*}{0.750} \\
\hline & Yes & $7 \pm 23.3 \%$ & $6 \pm 20.0 \%$ & \\
\hline \multirow{4}{*}{ Breath-Holding } & None & $18 \pm 60.0 \%$ & $24 \pm 80.0 \%$ & \multirow{4}{*}{0.091} \\
\hline & Mild & $5 \pm 16.7 \%$ & $2 \pm 6.7 \%$ & \\
\hline & Moderate & $6 \pm 20.0 \%$ & $3 \pm 10.0 \%$ & \\
\hline & Severe & $1 \pm 3.3 \%$ & $1 \pm 3.3 \%$ & \\
\hline \multirow{4}{*}{ Purposeful Movements } & None & $19 \pm 63.3 \%$ & $24 \pm 80.0 \%$ & \multirow{4}{*}{0.152} \\
\hline & Mild & $5 \pm 16.7 \%$ & $3 \pm 10.0 \%$ & \\
\hline & Moderate & $4 \pm 13.3 \%$ & $3 \pm 10.0 \%$ & \\
\hline & Severe & $2 \pm 6.7 \%$ & $0 \pm 0.0 \%$ & \\
\hline \multirow[t]{2}{*}{ Requiring of Secretions Removal } & No & $14 \pm 46.7 \%$ & $22 \pm 73.3 \%$ & \multirow[t]{2}{*}{0.035} \\
\hline & Yes & $16 \pm 53.3 \%$ & $8 \pm 26.7 \%$ & \\
\hline
\end{tabular}

Chi-square test.

Any differences were not detected in HR values in pre-op first and fourth minutes neither in Group D nor in Group $S(p>0.05)$. HR values in minutes of 2- 3- 56- 7- 8- 9- 10 were higher in Group $D$ than Group $S(p<$ 0.05 ) (Table 4 and Figure 2).

Any differences were not detected in MAP values in pre-op and sixth minute neither in Group D nor in Group $S(p>0.05)$. MAP values in minutes of 1- 2- 3- 4- 5- 78- 9- 10 were higher in Group D than Group $S(p<0.05)$ (Table 5 and Figure 3).
In group evaluation, $\mathrm{SpO}_{2}$ value in Group $\mathrm{D}$ was not different from pre-op. value in minutes of 120-150210-240- 270 ( $p>0.05)$. And in other times, $\mathrm{SpO}_{2}$ value was higher compared to pre-op. measured value ( $p<$ $0.05)$. HR value was higher compared to pre-op. measured value at all times $(p<0.05)$. MAP value was higher compared to pre-op. measured value at all times $(p<$ $0.05) . \mathrm{SpO}_{2}$ value in Group $\mathrm{S}$ was not different from preop. value in minutes of 120-150-180- 210 ( $p>0.05$ ). And in other times, $\mathrm{SpO}_{2}$ value was higher compared to 


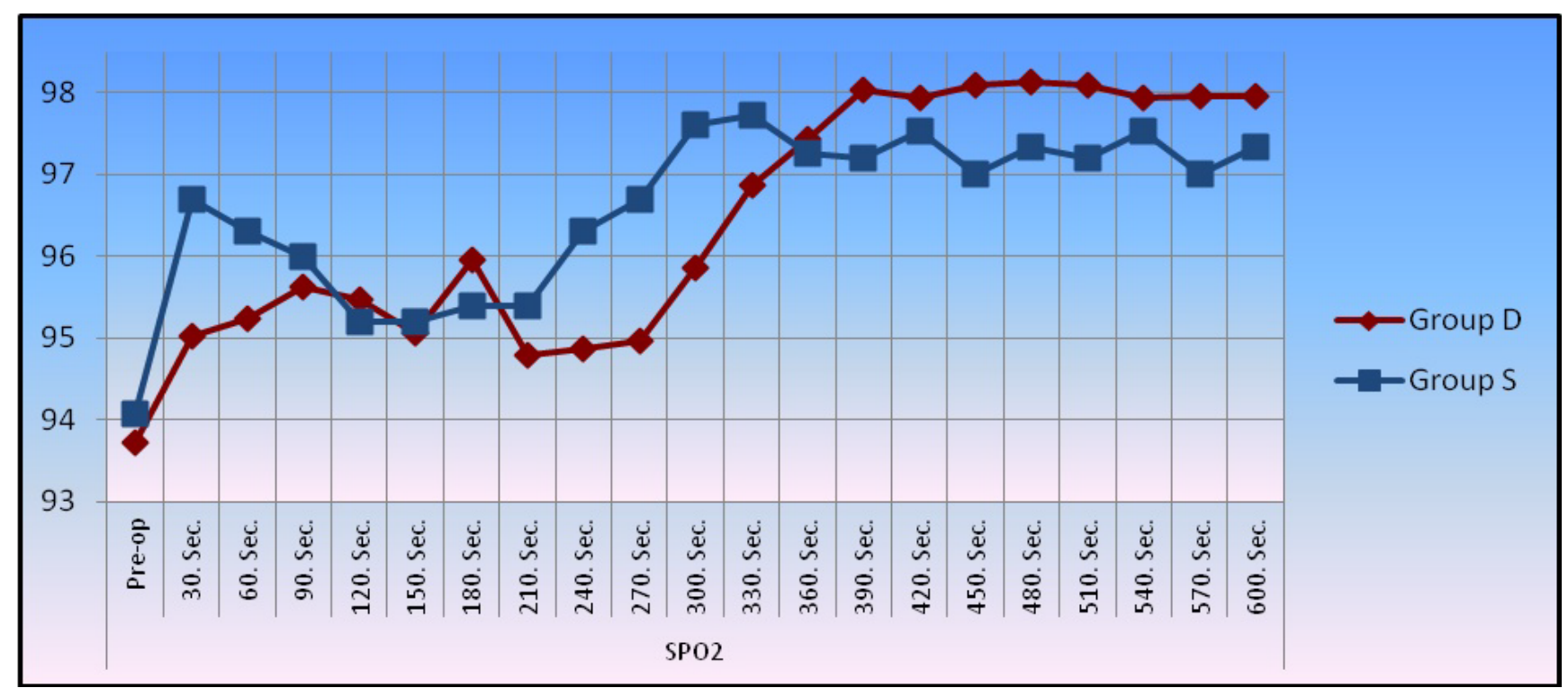

Figure 1: $\mathrm{SpO}_{2}$ values in Group $\mathrm{S}$ and Group D.

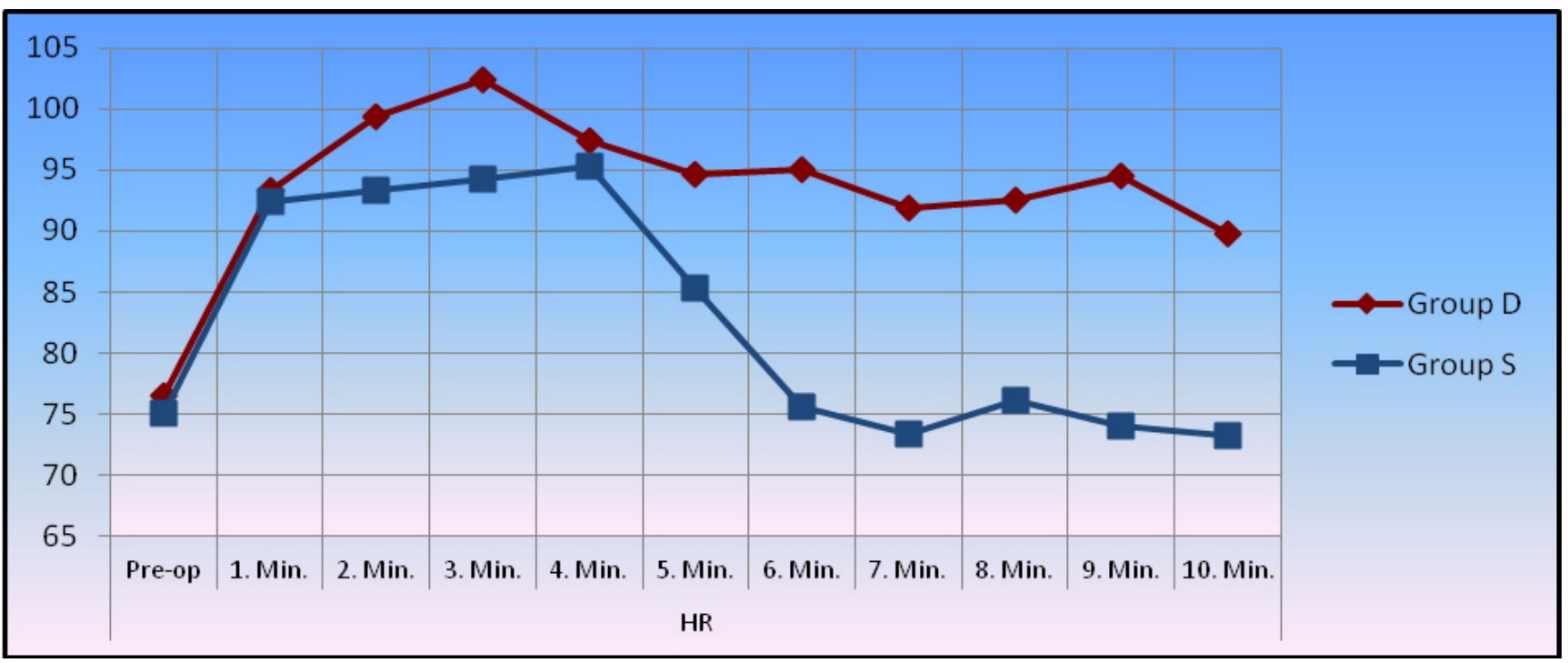

Figure 2: HR values in Group D and Group S.

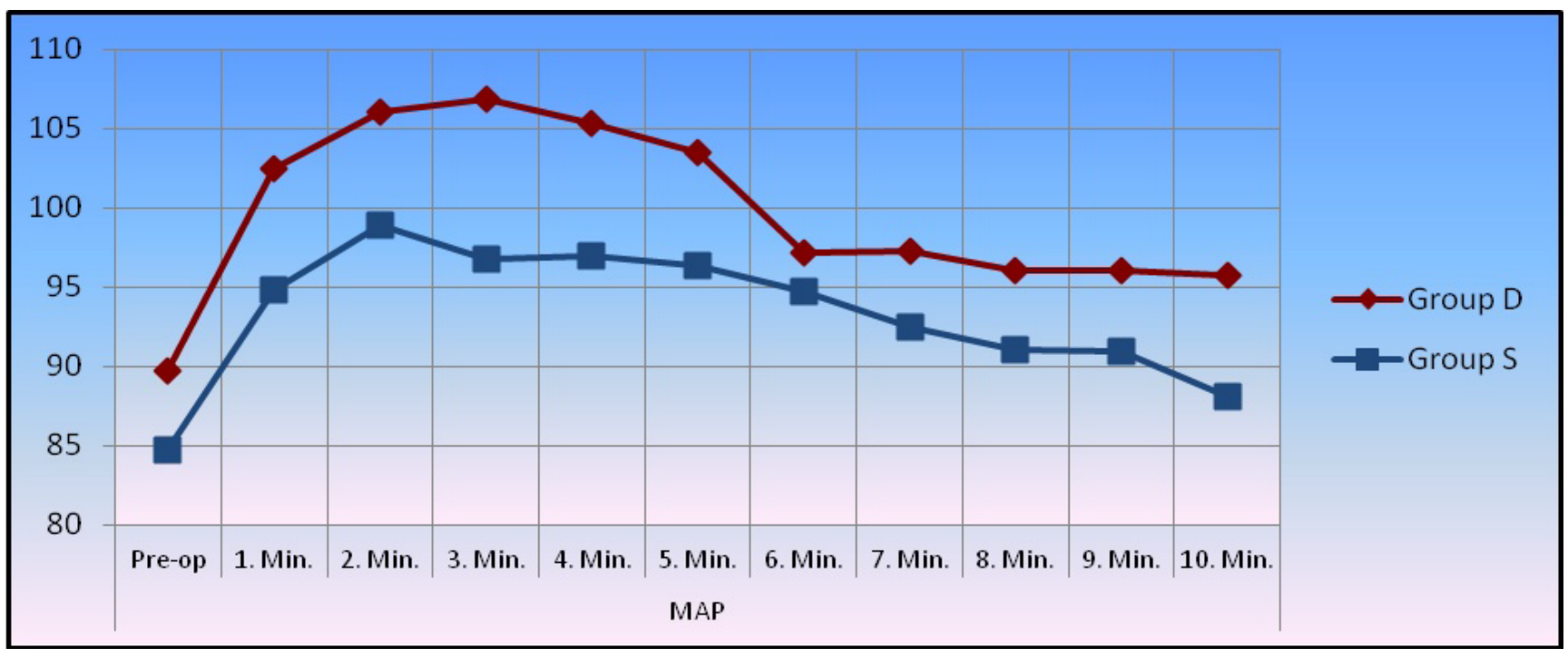

Figure 3: MAP values in Group D and Group S. 
Table 3: Any differences were not detected in $\mathrm{SpO}_{2}$ values in seconds of pre-op, 60, 90, 120, 150, 180, 210, 240, 270, 360, 420 neither in Group D nor in Group S ( $p>0.05)$. $\mathrm{SpO}_{2}$ values in seconds of $30,300,360$ were lower in Group D than Group $\mathrm{S}(\mathrm{p}<0.05) . \mathrm{SpO}_{2}$ values in seconds of $390,450,480,510$, 540,570 were higher in Group D than Group S $(p<0.05)$. $\mathrm{SpO}_{2}$ values in Group $S$ were higher till the $360^{\text {th }}$ second but after the $360^{\text {th }}$ second $\mathrm{SpO}_{2}$ values in Group $\mathrm{D}$ became higher. $\left(\mathrm{SpO}_{2}\right.$ : Oxygen saturation).

\begin{tabular}{|c|c|c|c|}
\hline & Group D & Group S & p \\
\hline & Mean \pm s.d. & Mean \pm s.d. & \\
\hline $\mathrm{SPO}_{2}$-pre & $93.7 \pm 1.3$ & $94.1 \pm 1.2$ & 0.304 \\
\hline $\mathrm{SPO}_{2}-30$ & $95.0 \pm 2.9$ & $96.7 \pm 2.0$ & 0.011 \\
\hline $\mathrm{SPO}_{2}-60$ & $95.2 \pm 3.7$ & $96.3 \pm 3.4$ & 0.246 \\
\hline $\mathrm{SPO}_{2}-90$ & $95.6 \pm 4.0$ & $96.0 \pm 3.6$ & 0.711 \\
\hline $\mathrm{SPO}_{2}-120$ & $95.5 \pm 4.7$ & $95.2 \pm 4.2$ & 0.817 \\
\hline $\mathrm{SPO}_{2}-150$ & $95.1 \pm 4.2$ & $95.2 \pm 3.9$ & 0.898 \\
\hline $\mathrm{SPO}_{2}-180$ & $96.0 \pm 3.4$ & $95.4 \pm 4.6$ & 0.592 \\
\hline $\mathrm{SPO}_{2}-210$ & $94.8 \pm 4.4$ & $95.4 \pm 3.7$ & 0.568 \\
\hline $\mathrm{SPO}_{2}-240$ & $94.9 \pm 4.6$ & $96.3 \pm 2.7$ & 0.143 \\
\hline $\mathrm{SPO}_{2}-270$ & $95.0 \pm 4.4$ & $96.7 \pm 2.0$ & 0.054 \\
\hline $\mathrm{SPO}_{2}-300$ & $95.9 \pm 3.6$ & $97.6 \pm 1.0$ & 0.015 \\
\hline $\mathrm{SPO}_{2}-330$ & $96.9 \pm 1.8$ & $97.7 \pm 0.7$ & 0.017 \\
\hline $\mathrm{SPO}_{2}-360$ & $97.4 \pm 1.3$ & $97.3 \pm 1.2$ & 0.601 \\
\hline $\mathrm{SPO}_{2}-390$ & $98.0 \pm 1.2$ & $97.2 \pm 1.2$ & 0.010 \\
\hline $\mathrm{SPO}_{2}-420$ & $97.9 \pm 1.3$ & $97.5 \pm 0.7$ & 0.137 \\
\hline $\mathrm{SPO}_{2}-450$ & $98.1 \pm 1.3$ & $97.0 \pm 1.4$ & 0.003 \\
\hline $\mathrm{SPO}_{2}-480$ & $98.1 \pm 1.1$ & $97.3 \pm 1.0$ & 0.004 \\
\hline $\mathrm{SPO}_{2}-510$ & $98.1 \pm 1.2$ & $97.2 \pm 1.2$ & 0.004 \\
\hline $\mathrm{SPO}_{2}-540$ & $97.9 \pm 0.6$ & $97.5 \pm 0.7$ & 0.023 \\
\hline $\mathrm{SPO}_{2}-570$ & $98.0 \pm 1.1$ & $97.0 \pm 1.4$ & 0.004 \\
\hline $\mathrm{SPO}_{2}-600$ & $98.0 \pm 0.7$ & $97.3 \pm 1.0$ & 0.004 \\
\hline
\end{tabular}

Student $\mathrm{t}$ test.

Table 4: Any differences were not detected in $H R$ values in pre-op first and fourth minutes neither in Group $D$ nor in Group $S(p>0.05)$. HR values in minutes of 2-3-5-6-7-8-9-10 were higher in Group D than Group S ( $<0.05)$. (HR: Heart Rate).

\begin{tabular}{|l|l|l|l|}
\hline & Group D & Group S & p \\
\cline { 2 - 4 } & Mean \pm s.d. & Mean \pm s.d. & \\
\hline HRpre & $76.5 \pm 11.3$ & $75.1 \pm 10.1$ & 0.801 \\
\hline HR1 & $93.3 \pm 9.0$ & $92.4 \pm 11.9$ & 0.485 \\
\hline HR2 & $99.4 \pm 7.1$ & $93.4 \pm 11.9$ & $\mathbf{0 . 0 0 9}$ \\
\hline HR3 & $102.4 \pm 6.7$ & $94.3 \pm 11.9$ & $\mathbf{0 . 0 0 0}$ \\
\hline HR4 & $97.4 \pm 6.2$ & $95.3 \pm 11.9$ & 0.185 \\
\hline HR5 & $94.7 \pm 4.7$ & $85.3 \pm 11.9$ & $\mathbf{0 . 0 0 0}$ \\
\hline HR6 & $95.0 \pm 6.8$ & $75.6 \pm 11.1$ & $\mathbf{0 . 0 0 0}$ \\
\hline HR7 & $91.8 \pm 6.4$ & $73.4 \pm 12.0$ & $\mathbf{0 . 0 0 0}$ \\
\hline HR8 & $92.5 \pm 7.9$ & $76.1 \pm 11.1$ & $\mathbf{0 . 0 0 0}$ \\
\hline HR9 & $94.5 \pm 10.1$ & $74.0 \pm 11.7$ & $\mathbf{0 . 0 0 0}$ \\
\hline HR10 & $89.8 \pm 6.4$ & $73.2 \pm 10.5$ & $\mathbf{0 . 0 0 0}$ \\
\hline
\end{tabular}

Mann-whitney u test.
Table 5: Any differences were not detected in MAP values in pre-op and sixth minutes neither in Group D nor in Group $S(p>0.05)$. MAP values in minutes of 1-2-3-4-5-6-7-8-9-10 were higher in Group D than Group S ( $<0.05)$. (MAP: Mean Arterial Pressure).

\begin{tabular}{|l|l|l|l|}
\hline & Group D & Group S & p \\
\cline { 2 - 4 } & Mean \pm s.d. & Mean \pm s.d. & \\
\hline MAP pre & $89.7 \pm 10.7$ & $84.7 \pm 12.0$ & 0.136 \\
\hline MAP1 & $102.5 \pm 9.9$ & $94.9 \pm 11.1$ & $\mathbf{0 . 0 1 7}$ \\
\hline MAP2 & $106.1 \pm 11.6$ & $98.9 \pm 9.7$ & $\mathbf{0 . 0 1 2}$ \\
\hline MAP3 & $106.9 \pm 12.2$ & $96.8 \pm 8.1$ & $\mathbf{0 . 0 0 1}$ \\
\hline MAP4 & $105.4 \pm 11.5$ & $97.0 \pm 7.8$ & $\mathbf{0 . 0 0 4}$ \\
\hline MAP5 & $103.5 \pm 12.4$ & $96.3 \pm 8.3$ & $\mathbf{0 . 0 1 4}$ \\
\hline MAP6 & $97.2 \pm 10.1$ & $94.8 \pm 9.4$ & 0.324 \\
\hline MAP7 & $97.3 \pm 6.8$ & $92.5 \pm 9.3$ & $\mathbf{0 . 0 3 2}$ \\
\hline MAP8 & $96.0 \pm 7.2$ & $91.1 \pm 9.9$ & $\mathbf{0 . 0 3 0}$ \\
\hline MAP9 & $96.1 \pm 5.8$ & $90.9 \pm 8.5$ & $\mathbf{0 . 0 1 8}$ \\
\hline MAP10 & $95.7 \pm 3.5$ & $88.1 \pm 8.0$ & $\mathbf{0 . 0 0 0}$ \\
\hline
\end{tabular}

Mann-whitney u test.

pre-op. measured value $(p<0.05)$. HR value was higher compared to pre-op. measured value in minutes of 1 2- 3- 4- $5(p<0.05)$. After the sixth minute, it was not different from pre-op. value $(p<0.05)$. MAP value was higher than pre-op. measured value in minutes of 1-23- 4- 5- 6- 7- 8- $9(p<0.05)$ while it was not different from pre-op measured value in tenth minute $(p>0.05)$ (Table 6).

\section{Discussion}

Tracheostomized patients' anesthesia induction is a simple technique. Although these patients generally have a co-morbid disease, enabling airway security is very easy. By means of an appropriate-sized endotracheal tube or tracheal cannula implemented to trachea from current tracheostomy, airway security is enabled easily. It will be beneficial to make sedoanalgesia before it. Whether induction shall be by intravenous or inhalation depends on anesthetists. Both of the methods are commonly used in our practice.

During ENT surgery, II is commonly used for infants and children. II is a comfortable, quick, physiological and minimally traumatic technique $[11,12]$. Moreover in adults, II is also used as an alternative since there is a risk of losing airway control due to intravenous induction [13]. In II, induction time may be long and especially due to smoking, upper respiratory tract infection and irritable airway diseases, there may be coughing, laryngospasm and bronchospasm [14-16]. We studied that II with sevoflurane and/or desflurane in tracheostomized patients.

Desflurane is an inhalation agent that may cause airway irritation compared to sevoflurane [17]. Many studies are being made in literature in order to lower effects of desflurane. Nebulized lidocaine, intravenous 
Table 6: In group evaluation of HR, MAP, $\mathrm{SPO}_{2}$ values (HR: Heart Rate, MAP: Mean Arterial Pressure, SPO${ }_{2}$ : Oxygen Saturation).

\begin{tabular}{|c|c|c|c|c|c|}
\hline & Group D & Group S & & Group D & Group S \\
\hline & p & $\mathbf{p}$ & & $\mathbf{p}$ & $\mathbf{p}$ \\
\hline HR1 - HR pre & 0.000 & 0.000 & $\mathrm{SPO}_{2}$ pre $-\mathrm{SPO}_{2}-30$ & 0.028 & 0.000 \\
\hline HR2 - HR pre & 0.000 & 0.000 & $\mathrm{SPO}_{2}$ pre $-\mathrm{SPO}_{2}-60$ & 0.049 & 0.002 \\
\hline HR3 - HR pre & 0.000 & 0.000 & $\mathrm{SPO}_{2}$ pre $-\mathrm{SPO}_{2}-90$ & 0.027 & 0.009 \\
\hline HR4 - HR pre & 0.000 & 0.000 & $\mathrm{SPO}_{2}$ pre $-\mathrm{SPO}_{2}-120$ & 0.077 & 0.165 \\
\hline HR5 - HR pre & 0.000 & 0.000 & $\mathrm{SPO}_{2}$ pre $-\mathrm{SPO}_{2}-150$ & 0.129 & 0.144 \\
\hline HR6 - HR pre & 0.000 & 0.412 & $\mathrm{SPO}_{2}$ pre $-\mathrm{SPO}_{2}-180$ & 0.005 & 0.139 \\
\hline HR7 - HR pre & 0.000 & 0.191 & $\mathrm{SPO}_{2}$ pre $-\mathrm{SPO}_{2}-210$ & 0.232 & 0.084 \\
\hline HR8 - HR pre & 0.000 & 0.158 & $\mathrm{SPO}_{2}$ pre $-\mathrm{SPO}_{2}-240$ & 0.223 & 0.000 \\
\hline HR9 - HR pre & 0.000 & 0.413 & $\mathrm{SPO}_{2}$ pre $-\mathrm{SPO}_{2}-270$ & 0.165 & 0.000 \\
\hline \multirow[t]{2}{*}{ HR10 - HR pre } & 0.000 & 0.157 & $\mathrm{SPO}_{2}$ pre $-\mathrm{SPO}_{2}-300$ & 0.006 & 0.000 \\
\hline & & & $\mathrm{SPO}_{2}$ pre $-\mathrm{SPO}_{2}-330$ & 0.000 & 0.000 \\
\hline MAP1 - MAP pre & 0.000 & 0.000 & $\mathrm{SPO}_{2}$ pre $-\mathrm{SPO}_{2}-360$ & 0.000 & 0.000 \\
\hline MAP2 - MAP pre & 0.000 & 0.000 & $\mathrm{SPO}_{2}$ pre $-\mathrm{SPO}_{2}-390$ & 0.000 & 0.000 \\
\hline MAP3 - MAP pre & 0.000 & 0.000 & $\mathrm{SPO}_{2}$ pre $-\mathrm{SPO}_{2}-420$ & 0.000 & 0.000 \\
\hline MAP4 - MAP pre & 0.000 & 0.000 & $\mathrm{SPO}_{2}$ pre $-\mathrm{SPO}_{2}-450$ & 0.000 & 0.000 \\
\hline MAP5 - MAP pre & 0.000 & 0.000 & $\mathrm{SPO}_{2}$ pre $-\mathrm{SPO}_{2}-480$ & 0.000 & 0.000 \\
\hline MAP6 - MAP pre & 0.040 & 0.001 & $\mathrm{SPO}_{2}$ pre $-\mathrm{SPO}_{2}-510$ & 0.000 & 0.000 \\
\hline MAP7 - MAP pre & 0.004 & 0.011 & $\mathrm{SPO}_{2}$ pre $-\mathrm{SPO}_{2}-540$ & 0.000 & 0.000 \\
\hline MAP8 - MAP pre & 0.018 & 0.038 & $\mathrm{SPO}_{2}$ pre $-\mathrm{SPO}_{2}-570$ & 0.000 & 0.000 \\
\hline MAP9 - MAP pre & 0.012 & 0.031 & $\mathrm{SPO}_{2}$ pre $-\mathrm{SPO}_{2}-600$ & 0.000 & 0.000 \\
\hline MAP10 - MAP pre & 0.011 & 0.239 & & & \\
\hline
\end{tabular}

morphine, fentanyl and remifentanil administration used for II [10,18-20]. Beginning region of airway reflexes affected by desflurane is not known and it is emphasized that there may be more vulnerable larynx and/or small airways $[21,22]$. Since larynx known to be vulnerable is bypassed in studied tracheostomized patients, we may not have detected differences in airway complications like coughing, breath-holding and desaturation in neither group; besides, we did not also observed any difference in complication belonging to small airway like bronchospasm. Garry, et al. [23] applied desflurane and II which, they think, are rapid and reliable for direct laryngoscopy to a 62-year-old male patient who have been treated in the neck by radiation due to laryngeal tumor and have $4^{\text {th }}$ degree airway obstruction accompanied by stridor resulting from the formation of granulation tissue in subglottic and supraglottic regions; and II is evaluated as regular, sufficient and secure. Since then, in patients with similar pathology, desflurane has been used for inducing a fast and smooth anesthesia after anaesthetize airway topically $[24,25]$. It is possible to obtain fast and smooth anesthesia induction in patients having airway deficiency by benefitting from desflurane's low solubility in blood [26]. Rampil, et al. [27] induced anesthesia by desflurane until intubation became possible without using neuromuscular blockers in patients not administered sedative medication. The researchers observed small number of airway irritations with limited level during $\mathrm{II}$ and that $10-18$ minutes is required for induction. Most common respiratory complications were increases in secretion (25-45\%) and in coughing (38-56\%). And the most important complication was laryngospasm by $2 / 44$ rate. In our study, induction time was shorter; it may be due to our administration of midazolam and fentanyl before II. Incidences of respiratory effects during our study were similar. $16 \%$ coughing is observed in usage case of sevoflurane which is utilized for II both in infants and adults [28]. We detected $50 \%$ coughing incidence in tracheostomized patients when desflurane is used and $36 \%$ when sevoflurane is used; these incidences had been similar in patients not tracheostomized in former studies when desflurane is used but were in high incidence in those using sevoflurane.

It is widely accepted that II with desflurane is associated with respiratory system irritation as well as hypertension and tachycardia. The concentration of desflurane (much) bigger than 1.0 to $1.5 \mathrm{MAC}$ results in sympathetic excitation, hypertension and tachycardia [29]. These symptoms can modulated with intravenous opioids, beta-blocking drugs, alpha-2 agonists [30]. In recent study, tracheostomized patients to who we administered desflurane and II in accordance with literature have higher MAP and faster HR values than sevoflurane-administered ones. The administration of midazolam sedation and fentanyl analgesia before administering II did not prevent this hemodynamic situation. Whether with desflurane or sevoflurane, no com- 
plication occurred in our study to finish II in any patients or change the method.

It is known that larynx is a protective and defensive reflexogenic region in airway. Irritant receptors such as drive, pressure, and cold receptors have been clearly identified in larynx and tracheobronchial mucosa [31]. Laryngeal reflexes such as the cough reflex, expiration reflex, and laryngeal closure with apne protect the airways from aspiration. It is well-established knowledge that general anesthetics modify these reflexes, and the impairment of upper airway protective reflexes has been demonstrated [32,33]. It is possible that distal receptors in tracheobronchial mucosa is more adaptive or insensitive in tracheostomized patients [34].

As a result, in tracheostomized patients from whom larynx was bypassed, desflurane causes similar airway irritation with sevoflurane but as we known that II was more stable with sevoflurane than desflurane.

\section{References}

1. Zwass MS, Fisher DM, Welborn LG, Coté CJ, Davis PJ, et al. (1992) Induction and maintenance characteristics of anesthesia with desflurane and nitrious oxide in infants and children. Anesthesiology 76: 373-378.

2. Wissing $H$, Kuhn I, Rietbrock S, Fuhr U (2000) Pharmacokinetics of inhaled anaesthetics in a clinical setting: Comparison of desflurane, isoflurane, and sevoflurane. $\mathrm{Br} \mathrm{J}$ Anaesth 84: 443-449.

3. Young CJ, Apfelbaum JL (1995) Inhalational anesthetics: Desflurane and sevoflurane. J Clin Anesth 7: 564-577.

4. Golembiewski J (2004) Considerations in selecting an inhaled anesthetic agent: Case studies. Am J Health-Syst Pharm 61: 10-17.

5. Arain SR, Shankar H, Ebert TJ (2005) Desflurane enhances reactivity during the use of the laryngeal mask airway. Anesthesiology 103: 495-499.

6. Dikmen Y, Eminoglu E, Salihoglu Z, Demiroluk S (2003) Pulmonary mechanics during isoflurane, sevoflurane and desflurane anesthesia. Anaesthesia 58: 745-748.

7. Leung JM, Pastor DA (1998) Dissociation between haemodynamics and sympathetic activation during anaesthetic induction with desfluranes. Can J Anaesth 45: 533-540.

8. Preckel B, Müllenheim J, Hoff J, Obal D, Heiderhoff M, et al. (2004) Haemodynamic changes during halothane, sevoflurane and desflurane anaesthesia in dogs before and after the induction of severe heart failure. Eur J Anaesthesiol 21: 797-806.

9. Mishra S, Bhatnagar S, Jha RR, Singhal AK (2005) Airway management of patients undergoing oral cancer surgery: $A$ retrospective study. Eur J Anaesthesiol 22: 510-514.

10. Bunting HE, Kelly MC, Milligan KR (1995) Effect of nebulized lignocaine on airway irritation and haemodynamic changes during induction of anaesthesia with desflurane. $\mathrm{Br} J$ Anaesth 75: 631-633.

11. Welborn LG, Hannallah RS, Norden JM, Ruttimann UE, Callan CM (1996) Comparison of emergence and recovery characteristics of sevoflurane, desflurane, and halothane in pediatric ambulatory patients. Anesth Analg 83: 917-920.
12. Taylor RH, Lerman J (1992) Induction, maintenance and recovery characteristics of desflurane in infants and children. Can J Anaesth 39: 6-13.

13. Ovassapian A, Tuncbilek M, Weitzel EK, Joshi CW (2005) Airway management in adult patients with deep neck infections: A case series and review of the literature. Anesth Analg 100: 585-589.

14. Smiley RM (1992) An overview of induction and emergence characteristics of desflurane in pediatric, adult, and geriatric patients. Anesth Analg 75: 38-44.

15. Eger El II (2004) Characteristics of anesthetic agents used for induction and maintenance of general anesthesia. Am J Health-Syst Pharm 61: 3-10.

16. Smith AF, Rauf K (2001) Use of intravenous opioids to reduce airway irritation during induction of anaesthesia with desflurane. Br J Anaesth 86: 599-600.

17. Goff MJ, Arain SR, Ficke DJ, Uhrich TD, Ebert TJ (2000) Absence of bronchodilation during desflurane anesthesia: A comparison to sevoflurane and thiopental. Anesthesiology 93: 404-408.

18. Smith I (2001) Intravenous opioids reduce airway irritation during induction of anaesthesia with desflurane in adults. $\mathrm{Br}$ J Anaesth 86: 149-150.

19. Kong CF, Chew STH, Ip-Yam PC (2000) Intravenous opioids reduce airway irritation during induction of anaesthesia with desflurane in adults. $\mathrm{Br} \mathrm{J}$ Anaest 85: 364-367.

20. Lee J, Jung CW (2011) The target concentration of remifentanil to suppress the hemodynamic response to endotracheal intubation during inhalational induction with desflurane. Korean J Anesthesiol 60: 12-18.

21. Ebert TJ, Muzi M (1993) Sympathetic hyperactivity during desflurane anesthesia in healthy volunteers. A comparison with isoflurane. Anesthesiology 79: 444-453.

22. McKay RE, Bostrom A, Balea MC, McKay WR (2006) Airway responses during desflurane versus sevoflurane administration via a laryngeal mask airway in smokers. Anesth Analg 103: 1147-1154.

23. Garry B, Torelli G, Yarnell R (1995) Desflurane can be used to achieve smooth and rapid induction of anesthesia. Anesthesiology 82: 313-314.

24. Kocamanoglu IS, Sener EB, Ustun E, Tur A (2006) Effects of lidocaine and prednisolone on endoscopic rigid laryngoscopy. Laryngoscope 116: 23-27.

25. Tanaka A, Isono S, Ishikawa T, Nishino T (2005) Laryngeal reflex before and after placement of airway interventions: endotracheal tube and laryngeal mask airway. Anesthesiology 102: 20-25.

26. Sakai EM, Connolly LA, Klauck JA (2005) Inhalation anesthesiology and volatile liquid anesthetics: Focus on isoflurane, desflurane, and sevoflurane. Pharmacotherapy 25: 1773-1788.

27. Rampil IJ, Lockhart SH, Zwass MS, Peterson N, Yasuda N, et al. (1991) Clinical characteristics of desflurane in surgical patients: minimum alveolar concentration. Anesthesiology 74: 429-433.

28. Kelly RE, Hartman GS, Embree PB, Sharp G, Artusio JF (1993) Inhaled induction and emergence from desflurane anesthesia in the ambulatory surgical patient: The effect of premedication. Anesth Analg 77: 540-543.

29. Kim SH, Park SY, Chae WS, Jin HC, Lee JS, et al. (2010) Effect of desflurane at less than $1 \mathrm{MAC}$ on $\mathrm{QT}$ interval 
prolongation induced by tracheal intubation. $\mathrm{Br} \mathrm{J}$ Anaesth 104: 150-157.

30. Weiskopf RB, Eger El II, Noorani M, Daniel M (1994) Fentanyl, esmolol, and clonidine blunt the transient cardiovascular stimulation induced by desflrane in human. Anesthesiology 81: 1350-1355.

31. Sekizawa S, Tsubone H, Hishida N, Kuwahara M, Sugano $S$ (1997) The afferent activity of the superior laryngeal nerve, and respiratory reflexes specifically responding to intralaryngeal pressure changes in anesthetized shiba goats. J Vet Med Sci 59: 885-890.
32. Hedenqvist $\mathrm{P}$, Roughan JV, Antunes L, Orr H, Flecknell PA (2001) Induction of anaesthesia with desflurane and isoflurane in the rabbit. Lab Anim 35: 172-179.

33. Wu YK, Tsai YH, Lan CC, Huang CY, Lee CH, et al. (2010) Prolonged mechanical ventilation in a respiratory-care setting: A comparison of outcome between tracheostomized and translarygeal intubated patients. Critical Care 14: R26.

34. Davis K, Campbell RS, Johannigman JA, Valente JF, Branson RD (1999) Changes in respiratory mechanics after tracheostomy. Arch Surg 134: 59-62. 